\title{
Factores que influyen en el emprendimiento de un micronegocio familiar en México
}

\author{
Recibido: mayo, 01 de 2017 - Aprobado: abril, 20 de 2018
}

Doi: http://dx.doi.org/10.12804/revistas.urosario.edu.co/economia/a.6816

\author{
Elías Alvarado Lagunas* \\ Jeyle Ortiz Rodríguez ${ }^{\dagger}$ \\ Dionicio Morales Ramírez $\ddagger$
}

\section{Resumen}

En el presente artículo se presentan los resultados de una caracterización de los micronegocios en México, efectuada mediante el uso de un modelo de elección discreta binaria, que permite determinar el efecto de los motivos por los que se inicia un micronegocio sobre la probabilidad de que un sujeto se encuentre en un micronegocio familiar. Para llevar a cabo este estudio se utiliza la Encuesta Nacional de Micronegocios del 2012, base de datos generada por el Instituto Nacional de Estadística y Geografía. Entre los resultados se encontró que los principales motivos que tienen los empresarios mexicanos para emprender un micronegocio familiar son mejorar y complementar el ingreso familiar y que los hombres casados son quienes más emprenden este tipo de asociación de negocio.

Palabras clave: micronegocio, negocio familiar, modelo logit.

Clasificación JEL: L21, L26, M21

* Profesor(es)-Investigador(es) de la Facultad de Contaduría Pública y Administración, Universidad Autónoma de Nuevo León, México. Correo electrónico: eliaxalvarado@ gmail.com

+ Profesor(es)-Investigador(es) de la Facultad de Contaduría Pública y Administración, Universidad Autónoma de Nuevo León, México.

$\ddagger$ Docente del Centro de Investigaciones Sociales, Universidad Autónoma de Tamaulipas, México.

Cómo citar este artículo: Alvarado Laguna, E., Ortiz Rodríguez, J. \& Morales Ramírez, D. (2018). Factores que influyen en el emprendimiento de un micronegocio familiar en México. Revista de Economía del Rosario, 21(1), 153-180.

Doi: http://dx.doi.org/10.12804/revistas.urosario.edu.co/economia/a.6816 


\title{
Determinants of Family Entrepreneurship in Small Businesses in Mexico
}

\begin{abstract}
Using a binary discrete choice model, this article aims to determine the effects of owner's motivation for launching a micro-enterprise on the likelihood of having a family microenterprise in Mexico. We use the National Survey on Micro-Enterprise 2012 collected by the National Institute of Statistics and Geography. Results show that the main reasons that Mexican entrepreneurs have for launching a family micro-enterprise are to improve and contribute to the family income, and that married men are more likely to start a family micro-enterprise than women or single men.
\end{abstract}

Keywords: microbusiness, family business, Logit model.

JEL Classification: L21, L26, M21.

\section{Fatores que influenciam no empreendimento de um micronegócio familiar no México}

\section{Resumo}

No presente artigo se apresentam os resultados de uma caracterização dos micronegócios no México, efetuada mediante o uso de um modelo de eleição discreta binária, que permite determinar o efeito dos motivos pelos que se inicia um micronegócio sobre a probabilidade de que um sujeito se encontre em um micronegócio familiar. Para levar a cabo este estudo utiliza-se o Inquérito Nacional de Micronegócios do Ano 2012, base de dados gerada pelo Instituto Nacional de Estatística e Geografia. Entre os resultados encontrou-se que os principais motivos que têm os empresários mexicanos para empreender um micronegócio familiar são melhorar e complementar o ingresso familiar e que os homens casados são quem mais empreendem este tipo de associação de negócio.

Palavras-chave: micronegócio, negócio familiar, modelo logit.

Classificação JEL: L21, L26, M21. 


\section{Introducción}

En los últimos años, el tema de emprendimiento o actividad emprendedora ha tenido un interés creciente en el ámbito académico y empresarial en México. Guzmán y Trujillo (2008) señalan que existen dos tipos de emprendimiento: el social y el de negocios. El primero tiene como objetivo la creación del valor social sostenible, mientras que el segundo se refiere a aquellas actividades innovadoras que crean incentivos económicos para el emprendedor.

Sin duda, la actividad emprendedora con enfoque empresarial o de negocios en México es uno de los principales mecanismos que favorece el crecimiento económico y la creación de empleo del país. Basta con señalar los datos que muestra el Instituto Nacional de Estadística y Geografía (Inegi, 2012a) al sostener que existen alrededor de 4 millones 15 mil unidades empresariales, de las cuales $99,8 \%$ son micro, pequeñas y medianas empresas -Mipymes- que en conjunto generan el $52 \%$ del producto interno bruto —PIB- y el $72 \%$ del empleo en el país.

Las Mipymes constituyen la columna vertebral de la economía nacional debido a los acuerdos comerciales y al apoyo que reciben los empresarios en sus negocios o proyectos productivos por parte de los gobiernos estatal y federal. Sin embargo, en lo que se refiere a los micronegocios familiares, se puede argumentar que constituyen un sector de la economía muy disperso y diversificado; además, sigue existiendo mucha volatilidad en la creación y el crecimiento de estos negocios, pues, según datos de la Secretaría de Economía de México, las posibilidades de que estas empresas o negocios se mantengan con éxito en el mercado nacional rondan, en promedio, entre los dos y tres años. Lo anterior se deriva de diferentes causas, como: falta de planeación e información; deficiencias en la operación y la producción; deficiencias financieras, de visión, de gestión interna y en los apoyos para la exportación; corrupción, entre otras (Dussel, 2004; Secretaría de Economía, 2013).

Desde este contexto, se reconoce la importancia de la generación y la participación de las Mipymes familiares en el territorio mexicano. Por ello, en la presente investigación nos enfocaremos en los micronegocios familiares, los cuales serán aquellas unidades económicas de hasta seis personas para las industrias extractiva, de la construcción, servicios, transportes y comercio, y 16 personas para la industria manufacturera, en ambas incluyendo al dueño (Inegi, 2012b).

El Inegi, a través de la Encuesta Nacional de Micronegocios -Enamin-, recaba información directamente de los dueños de los micronegocios sobre las principales características de recursos productivos, organización, monto y distribución de gastos e ingresos. Tomando como referencia la Enamin (Inegi, 
2012b), ${ }^{1}$ se buscaron aquellos ítems que argumentan las razones para haber iniciado los negocios y las expectativas de continuar con él. Por lo tanto, el presente trabajo pretende conocer ¿cuáles son los factores determinantes por los que se inicia un micronegocio familiar? A partir de esta interrogante, se analizan las razones que tienen los microempresarios para continuar en este tipo de asociación, ya que prevalece el estereotipo que señala que las empresas de asociación familiar no crecen (Danco, 1980, citado en Ward, 1990). ${ }^{2}$

En México, los estudios sobre la caracterización de los microempresarios referente a cómo iniciaron un negocio familiar son realizados desde una perspectiva cualitativa y, en el mejor de los casos, utilizando estadística descriptiva. De ahí surge el interés de hacer una aportación a la investigación de este tema, pero con un enfoque cuantitativo. En este caso, se utiliza un modelo de elección discreta binaria ${ }^{3}$, el cual permitirá determinar el efecto de los motivos principales para crear un micronegocio sobre la probabilidad de que un sujeto se encuentre en una determinada asociación de negocio.

\section{Revisión de literatura}

Sin duda alguna, el tema de la generación, el fomento y el apoyo a las Mipymes en los países en desarrollo ha adquirido una mayor relevancia en todos los sectores económicos de cualquier nación, ya que, de ser impulsados adecuadamente los programas o políticas basadas en la creación de empresas, no solo se fomentarán el empleo, la inversión, la innovación y la competitividad, sino que habrá un mayor crecimiento económico que contribuirá a lograr el deseado bienestar social.

1 La Enamin es el resultado del trabajo conjunto de la Secretaría del Trabajo y Previsión Social — STPS - con el Instituto Nacional de Estadística y Geografía - Inegi-. Se tiene información disponible para 1992, 1994, 1996, 1998, 2002, 2008, 2010 y 2012. En el presente estudio se decide trabajar con el último año debido a que cuenta con los ítems necesarios para el modelo que se pretende desarrollar, además de que los instrumentos de los años anteriores son diferentes y no coinciden con el propósito de la presente investigación, ya que la cobertura de las primeras encuestas sufrieron un cambio importante al pasar de urbana a nacional. Otra razón para elegir el 2012 es que es el periodo más reciente, siendo esta encuesta consolidada y actualizada respecto a los micronegocios de las zonas urbanas y rurales de México. Es importante mencionar que esta encuesta está diseñada para garantizar su representatividad a nivel nacional.

2 En el presente estudio la forma de asociación se clasifica en: familiar, no familiar y mixta.

3 Martínez (2008) señala que existen dos métodos para desarrollar un modelo de probabilidad para una variable de respuesta binaria: el modelo logit y el modelo probit. En el presente trabajo se utilizará el primero de ellos. 
Audretsch y Fritsch (2002), Fölster (2000), Klepper (1996), Audretsch (1995), Hopenhayn (1992) y Lambson (1991) sostienen que la actividad emprendedora juega un papel muy importante en el crecimiento económico de un país, ya que si los gobiernos apoyan y fomentan la creación de nuevas empresas, será mayor el nivel del crecimiento económico del país. En este mismo sentido, Reynolds, Bygrave, Autio, Cox y Hay (2002) señalan que, para lograr lo anterior, el gobierno central de cada país deberá formular políticas públicas más efectivas para la creación de nuevos negocios o empresas, focalizando específicamente las actividades emprendedoras de cada sociedad.

En la discusión teórica sobre la actividad emprendedora ha habido diversos debates conceptuales y metodológicos, ya que son muchas las corrientes que argumentan o respaldan las diferentes formas de identificar y cuantificar el emprendimiento social o empresarial. Existe una gran diversidad de estudios que tratan de explicar estos fenómenos. En el presente trabajo nos enfocamos en el ámbito empresarial, particularmente en la actividad emprendedora en los micronegocios. La base teórica sobre el fenómeno de la creación de empresas por la actividad emprendedora está vinculada con los trabajos clásicos de Audretsch y Fristsch (1994), y Keeble y Walker (1994), quienes consideran que medir el término de emprendimiento en cualquier actividad empresarial no es una tarea fácil, ya que una de las principales críticas apunta hacia su naturaleza intangible. Además, señalan que la definición y la medición de este término pueden ser abordadas desde un enfoque estructural o social y personal. El primero de ellos se refiere a aquellos factores del entorno que pueden influir directa e indirectamente en la actividad empresarial, tal es el caso de la cultura empresarial de la sociedad, la estructura sectorial de la actividad económica, la coyuntura económica, el entorno financiero y el capital social, entre otros. Mientras, los factores personales se refieren al entorno familiar, la insatisfacción con el trabajo asalariado, la oportunidad y la capacidad de financiación, la necesidad de conseguir logros, la edad, la formación profesional y la seguridad personal, entre otros.

Algunos estudios sobre la actividad emprendedora, la influencia, la motivación y la oportunidad de negocio se han enfocado principalmente en identificar aquellos aspectos o razones que los empresarios consideran relevantes para crear una empresa. A continuación se describen algunos estudios realizados a nivel internacional y en México para identificar los factores determinantes del inicio o cierre de un negocio.

Alonso y Galve (2008), Álvarez y Valencia (2008), García, Martínez y Fernández (2010), y Kantis (2003) señalan que toda iniciativa o actividad emprendedora en la creación de una nueva empresa o negocio depende de la motivación y la observación que hace la persona de los cambios en su 
entorno. Es decir, las personas emprendedoras son aquellas que constantemente están buscando oportunidades y cuentan con un carisma especial para encontrar las relaciones sociales (contactos o enlaces) que dependen o se desencadenan de su negocio; tal es el caso de la búsqueda o lealtad de sus clientes y proveedores (Gómez, 2007).

En este mismo sentido, algunos estudios de caso demuestran que el emprendedor normalmente cuenta con siete características que influyen en la creación o el proceso exitoso de un nuevo negocio: 1) entusiasmo; 2) capacidad para asumir riesgos; 3) espíritu de sacrificio; 4) necesidad;5) ambición; 6) independencia; y 7) conocimiento (García, Álvarez \& Reyna, 2007). De igual forma, Entrialgo, Fernández y Vázquez (1999), Fernández y Junquera (2001), Quintana (2001) y Mintzberg, Ahlstrand y Lampel (1999) coinciden con los autores citados, pues argumentan que las características de la personalidad de los empresarios más exitosos son la necesidad de logros, la tolerancia a la ambigüedad, el control interno y la asunción de riesgos.

En este mismo contexto, Elston y Audretsch (2011), y Rodríguez (2006) determinan para Estados Unidos de América y Venezuela, respectivamente, que los factores económicos o fuentes de financiamiento son aspectos indispensables para llevar a cabo un proyecto emprendedor. Estos autores señalan que las tres fuentes de financiamiento iniciales de un empresario son los recursos propios o de la familia, de socios y de amigos. Al respecto, Gelderen, Bosma y Thurik (2001), Quintana (2001) y Pinillos (2001) sostienen que las características demográficas del empresario, desde una perspectiva psicológica, también son relevantes, por ejemplo: la edad, el estado civil, el nivel de educación, la experiencia laboral y personal, y los antecedentes familiares en la creación de empresas, entre otras.

Para el caso de México, se encuentra el estudio de Peña, Ríos y Salazar (2012), el cual señala que no todos los micronegocios son iguales - y mucho menos los familiares-, ya que las razones para comenzarlos son diferentes y dependen en muchas ocasiones de las oportunidades que se presentan para autoemplearse y tener independencia. Por lo tanto, las perspectivas de crecimiento de los micronegocios familiares son limitadas, dado que no se invierte en capital físico (infraestructura, maquinaria, herramienta, etcétera), debido a que a la mayoría de los microempresarios no le interesa obtener apoyo económico de alguna entidad financiera.

En este sentido, Bonfil (2003) establece que el pequeño empresario se aventura en el mundo emprendedor en busca de mejores oportunidades y un mejor ingreso, y como primera fuente de financiamiento recurre a los familiares y amigos. Lecuona (2009) menciona que los proveedores son agentes de suma importancia en el éxito de un micronegocio, ya que a través de ellos 
se obtienen los insumos o la materia prima del negocio, y ocupan en muchas ocasiones la posición principal como fuente de fondos del micronegocio.

Existen otros estudios que analizan desde una perspectiva cualitativa los factores que influyen en la creación de empresas. Tal es el caso de Dussel (2004), Gómez, García y Marín (2009), De la Garza et al. (2011), Casas e Ibarra (2013) y Nava (2013), quienes señalan que es necesario abordar el tema del emprendimiento de un negocio desde tres diferentes perspectivas: 1 ) factores motivacionales o valores; 2) factores económicos; y 3) factores de financiamiento. Estos autores concluyen que la creación y el éxito de una empresa depende de muchos factores socioeconómicos, siendo uno de los principales el tener una estructura de capital en óptimas condiciones, además de contar con apoyo de financiamiento para el desarrollo de empresas innovadoras productivas y de servicios.

Según los estudios referidos, se puede señalar que la identificación de los factores que influyen en la creación de micronegocios puede ser abordada desde diferentes enfoques: cualitativos y cuantitativos. A continuación se explica brevemente el modelo que se sigue en esta investigación para cuantificar los principales factores determinantes para emprender un micronegocio familiar en México.

\section{Datos}

Para poder determinar los factores que inciden en la creación de un micronegocio familiar se utilizó la Enamin correspondiente al 2012. Esta encuesta es aplicada y publicada por el Inegi y contiene información detallada sobre las principales características de recursos productivos, organización, monto y distribución de gastos e ingresos efectuados por los dueños de los micronegocios en México. Adicionalmente, la Enamin cuenta con información específica sobre las razones de los microempresarios ${ }^{4}$ para iniciar los negocios considerados en la encuesta. En la Enamin, el tamaño de la población total fue de alrededor de 27 mil dueños de micronegocios distribuidos en todo el país bajo las modalidades de micronegocios familiares, no familiares y mixtos. Para el presente trabajo se utilizó una muestra de 1095 datos con las tres formas de asociación diferentes.

4 La Enamin denomina "microempresario" a aquella persona dueña de un micronegocio conformado por o que ocupa de una a seis personas incluyendo al dueño y hasta de 16 , si se trata de empresas en el sector manufacturero. 
Como se ha mencionado, en esta encuesta se obtuvo información directamente de los microempresarios, de manera que se resaltan las razones por las que estos iniciaron el micronegocio familiar, su financiamiento, los principales problemas que enfrentan, el ingreso salarial, el personal ocupado y sus planes para continuar con el negocio o no, entre otros aspectos.

En las siguientes secciones se muestran los estadísticos de frecuencia y descriptivos de la base de datos que se generó de la Enamin. En primera instancia, se presentan las características más representativas de los sujetos de estudio (sección 3.1). Posteriormente, se señalan las estadísticas descriptivas de las variables explicativas a utilizar en el modelo de elección discreta (sección 3.2).

\subsection{Estadísticos de frecuencia}

Las tablas 1, 2 y 3 presentan los estadísticos descriptivos de frecuencia de la base de datos, tomando en cuenta su respectivo factor de expansión ${ }^{5}$ dada la forma de asociación del micronegocio - en nuestro caso, el familiar-. Es conveniente destacar que los datos se recabaron casi de manera equitativa entre hombres $(48,5 \%)$ y mujeres $(51,5 \%)$, y que la mayoría de los microempresarios encuestados reportó tener más de 41 años de edad. La mayor parte de estos microempresarios argumentó pertenecer al sector comercio, seguido de la rama de servicios. Así mismo, muchos de estos microempresarios señalaron que su ingreso promedio mensual es de 1904,66 pesos, obteniendo mejor ingreso el sector servicios (4303,88 pesos), seguido del sector comercio $(2460,52$ pesos). De igual manera, se observa que en la mayoría de los micronegocios se cuenta con un personal ocupado de dos a cinco personas.

Tabla 1. Características generales de los empresarios que tienen un micronegocio en México

\begin{tabular}{llrrrrrr}
\hline & & \multicolumn{2}{c}{ Familiar } & \multicolumn{2}{c}{ No familiar } & \multicolumn{2}{c}{ Mixta } \\
\cline { 3 - 8 } & Componente & Frecuencia & $\%$ & Frecuencia & $\%$ & Frecuencia & $\%$ \\
\hline \multirow{3}{*}{ Sexo } & Hombre & 160.226 & 48,5 & 81.834 & 73,3 & 6401 & 59,6 \\
& Mujer & 170.393 & 51,5 & 29.741 & 26,7 & 4332 & 40,4 \\
& Total & 330.619 & 100,0 & 111.575 & 100,0 & 10.733 & 100,0 \\
\hline
\end{tabular}

5 El factor de expansión se interpreta como la cantidad de personas en la población que representa una persona en la muestra. Es decir, la estimación de un total dado para una variable se obtiene, primero, ponderando el valor de la variable en cada persona por su factor de expansión y, luego, sumando todas las personas de la muestra. 


\begin{tabular}{|c|c|c|c|c|c|c|c|}
\hline & \multirow{2}{*}{ Componente } & \multicolumn{2}{|c|}{ Familiar } & \multicolumn{2}{|c|}{ No familiar } & \multicolumn{2}{|c|}{ Mixta } \\
\hline & & Frecuencia & $\%$ & Frecuencia & $\%$ & Frecuencia & $\%$ \\
\hline \multirow{5}{*}{ Edad } & Menos de 18 años & 1327 & 0,40 & 713 & 0,60 & 0,0 & 0,0 \\
\hline & De 18 a 28 años & 58.869 & 17,8 & 25.350 & 22,7 & 2533 & 23,6 \\
\hline & De 29 a 40 años & 112.179 & 33,9 & 37.473 & 33,6 & 4137 & 38,5 \\
\hline & Más de 41 años & 158.244 & 47,9 & 48.039 & 43,1 & 4063 & 37,9 \\
\hline & Total & 330.619 & 100,0 & 111.575 & 100,0 & 10.733 & 100,0 \\
\hline \multirow{5}{*}{$\begin{array}{l}\text { Sector } \\
\text { económico }\end{array}$} & Manufactura & 49.799 & 15,1 & 8835 & 7,9 & 1853 & 17,3 \\
\hline & Comercio & 138.875 & 42,0 & 11.674 & 10,5 & 3552 & 33,1 \\
\hline & Construcción & 9820 & 3,0 & 5272 & 4,7 & 140 & 1,3 \\
\hline & Servicios & 132.125 & 40,0 & 85.794 & 76,9 & 5188 & 48,3 \\
\hline & Total & 330.619 & 100,0 & 111.575 & 100,0 & 10.733 & 100,0 \\
\hline \multirow{4}{*}{$\begin{array}{l}\text { Ingreso } \\
\text { promedio } \\
\text { mensual }\end{array}$} & Manufactura & 854,23 & 11,2 & 1079,39 & 11,5 & $23.511,15$ & 76,7 \\
\hline & Comercio & 2460,52 & 32,3 & 1306,70 & 13,9 & 3277,53 & 10,7 \\
\hline & Servicios/construcción & 4303,88 & 56,5 & 7024,15 & 74,6 & 3857,96 & 12,6 \\
\hline & Total & 7618,63 & 100,0 & 9410,24 & 100,0 & $30.646,64$ & 100,0 \\
\hline \multirow{10}{*}{$\begin{array}{l}\text { Personal } \\
\text { ocupado }\end{array}$} & 1 persona & 18.832 & 10,6 & 1320 & 1,9 & 555 & 8,8 \\
\hline & 2 a 5 personas & 76.706 & 43,0 & 24.013 & 35,2 & 548 & 8,7 \\
\hline & 6 a 10 personas & 18.862 & 10,5 & 8439 & 12,4 & 977 & 15,6 \\
\hline & 11 a 15 personas & 12.049 & 6,8 & 3569 & 5,2 & 307 & 4,9 \\
\hline & 16 a 20 personas & 7114 & 3,9 & 3786 & 5,5 & 554 & 8,8 \\
\hline & 21 a 30 personas & 4126 & 2,4 & 5519 & 8,1 & 1630 & 25,9 \\
\hline & 31 a 50 personas & 12.263 & 6,9 & 1638 & 2,4 & 0,0 & 0,0 \\
\hline & Más de 51 personas & 27.646 & 15,5 & 18.544 & 27,2 & 1715 & 27,3 \\
\hline & No sabe & 755 & 0,40 & 1399 & 2,1 & 0,0 & 0,0 \\
\hline & Total & 178.353 & 100,0 & 68.227 & 100,0 & 6286 & 100,0 \\
\hline
\end{tabular}

*El ingreso está medido en pesos mexicanos y el tipo de cambio peso-dólar en ese año era de 12,99 pesos por dólar. ** El total puede variar debido al factor de expansión de cada pregunta y al número de valores perdidos. Fuente: elaboración propia con datos de la Enamin (Inegi, 2012b)

En la tabla 2 se muestran los porcentajes del micronegocio según los motivos por los que fueron emprendidos, según la Enamin. De manera general, se aprecia que el motivo más frecuente para emprender un micronegocio fue "mejorar el ingreso familiar" y "complementar el ingreso familiar", mientras que el de menor importancia fue "no tenía la escolaridad requerida para un 
empleo". Por otro lado, la mayoría de los microempresarios en México ha emprendido un micronegocio gracias a los ahorros personales destinados para su proyecto de vida (51,1\%); así mismo, el 10,8\% menciona que no hubiera podido emprender el micronegocio sin el apoyo de familiares y amigos.

En lo que respecta a las formas de asociación del micronegocio, se puede apreciar que el motivo por el que las personas forman un negocio familiar (representado con el número I) es "mejorar su ingreso", mientras que las personas que se encuentran en la asociación no familiar (representado con el número II) argumentan que lo llevan a cabo "para ejercer su oficio o carrera". Por último, respecto a la asociación mixta (representado con el III), las personas señalan que el motivo principal para llevar a cabo un micronegocio fue que se necesitaba "complementar el ingreso familiar".

De igual manera, se puede observar que, en el rubro para financiar un micronegocio, la mayoría de los microempresarios en las tres diferentes formas de asociación (I, II y III) argumenta que para emprenderlo ocupó sus "ahorros personales", seguido del "préstamo de familiares y amigos".

Tabla 2. Distribución de los micronegocios según los motivos para su emprendimiento

\begin{tabular}{|c|c|c|c|c|c|c|c|c|c|}
\hline \multirow{2}{*}{ Motivos } & \multirow{2}{*}{ Global } & \multicolumn{3}{|c|}{ Asociación } & \multirow{2}{*}{$\begin{array}{l}\text { Financia- } \\
\text { miento }\end{array}$} & \multirow{2}{*}{ Global } & \multicolumn{3}{|c|}{ Asociación } \\
\hline & & I & II & III & & & I & II & III \\
\hline \multirow{2}{*}{$\begin{array}{l}\text { Por tradición } \\
\text { familiar }\end{array}$} & 47.489 & 41.384 & 5114 & 991 & \multirow{2}{*}{$\begin{array}{l}\text { Banca } \\
\text { comercial }\end{array}$} & 15.385 & 13.953 & 1194 & 238 \\
\hline & $(10,5)$ & $(12,5)$ & $(4,6)$ & $(9,2)$ & & $(3,4)$ & $(4,2)$ & $(1,1)$ & $(2,2)$ \\
\hline \multirow{2}{*}{$\begin{array}{l}\text { Complementar } \\
\text { el ingreso } \\
\text { familiar }\end{array}$} & 71.066 & 58.962 & 9892 & 2212 & \multirow{2}{*}{$\begin{array}{l}\text { Banca de } \\
\text { desarrollo }\end{array}$} & 315 & 315 & 0,0 & 0,0 \\
\hline & $(15,7)$ & $(17,8)$ & $(8,9)$ & $(20,6)$ & & $(0,1)$ & $(0,1)$ & $(0,0)$ & $(0,0)$ \\
\hline \multirow{2}{*}{$\begin{array}{l}\text { Mejorar el } \\
\text { ingreso }\end{array}$} & 102.743 & 82.259 & 18.520 & 1964 & \multirow{2}{*}{$\begin{array}{l}\text { Programa } \\
\text { de gobierno }\end{array}$} & 3533 & 617 & 1852 & 1.064 \\
\hline & $(22,7)$ & $(24,9)$ & $(16,6)$ & $(18,3)$ & & $(0,8)$ & $(0,2)$ & $(1,7)$ & $(9,9)$ \\
\hline \multirow{2}{*}{$\begin{array}{l}\text { Encontró una } \\
\text { buena oportuni- } \\
\text { dad de negocio }\end{array}$} & 22.320 & 16.317 & 4852 & 1145 & \multirow{2}{*}{$\begin{array}{l}\text { Cajas } \\
\text { populares }\end{array}$} & 12.988 & 11.593 & 1395 & 0,0 \\
\hline & $(4,9)$ & $(4,9)$ & $(4,4)$ & $(10,7)$ & & $(2,9)$ & $(3,5)$ & $(1,3)$ & $(0,0)$ \\
\hline \multirow{2}{*}{$\begin{array}{l}\text { Para ejercer su } \\
\text { oficio o carrera }\end{array}$} & 56.462 & 22.800 & 32.235 & 1427 & \multirow{2}{*}{$\begin{array}{l}\text { Crédito } \\
\text { de provee- } \\
\text { dores }\end{array}$} & 1330 & 1155 & 175 & 0,0 \\
\hline & $(12,5)$ & $(6,9)$ & $(28,9)$ & $(13,3)$ & & $(0,3)$ & $(0,3)$ & $(0,2)$ & $(0,0)$ \\
\hline \multirow{2}{*}{$\begin{array}{l}\text { Fue la única ma- } \\
\text { nera que tuvo } \\
\text { para obtener un } \\
\text { ingreso }\end{array}$} & 46.920 & 34.100 & 11.437 & 1383 & \multirow{2}{*}{$\begin{array}{l}\text { Prestamis- } \\
\text { tas particu- } \\
\text { lares }\end{array}$} & 2182 & 1553 & 629 & 0,0 \\
\hline & $(10,4)$ & $(10,3)$ & $(10,3)$ & $(12,9)$ & & $(0,5)$ & $(0,5)$ & $(0,6)$ & $(0,0)$ \\
\hline
\end{tabular}




\begin{tabular}{|c|c|c|c|c|c|c|c|c|c|}
\hline \multirow{2}{*}{ Motivos } & \multirow{2}{*}{ Global } & \multicolumn{3}{|c|}{ Asociación } & \multirow{2}{*}{$\begin{array}{c}\text { Financia- } \\
\text { miento }\end{array}$} & \multirow{2}{*}{ Global } & \multicolumn{3}{|c|}{ Asociación } \\
\hline & & I & II & III & & & I & II & III \\
\hline \multirow{2}{*}{$\begin{array}{l}\text { No tenía la } \\
\text { experiencia } \\
\text { requerida para } \\
\text { un empleo }\end{array}$} & 436 & 436 & 0,0 & 0,0 & \multirow{2}{*}{$\begin{array}{l}\text { Préstamo } \\
\text { de amigos } \\
\text { o parientes }\end{array}$} & 49.007 & 38.382 & 8087 & 2538 \\
\hline & $(0,1)$ & $(0,1)$ & $(0,0)$ & $(0,0)$ & & $(10,8)$ & $(11,6)$ & $(7,2)$ & $(23,6)$ \\
\hline \multirow{2}{*}{$\begin{array}{l}\text { No tenía la } \\
\text { escolaridad } \\
\text { requerida para } \\
\text { un empleo }\end{array}$} & 406 & 406 & 0,0 & 0,0 & \multirow{2}{*}{$\begin{array}{l}\text { Venta, } \\
\text { hipoteca o } \\
\text { empeño de } \\
\text { sus bienes }\end{array}$} & 3708 & 2717 & 991 & 0,0 \\
\hline & $(0,1)$ & $(0,1)$ & $(0,0)$ & $(0,0)$ & & $(0,8)$ & $(0,8)$ & $(0,9)$ & $(0,0)$ \\
\hline \multirow{2}{*}{$\begin{array}{l}\text { Estaba sobreca- } \\
\text { pacitado para } \\
\text { un empleo }\end{array}$} & 1049 & 0,0 & 1049 & 0,0 & \multirow{2}{*}{$\begin{array}{l}\text { Liquidación } \\
\text { del empleo } \\
\text { anterior }\end{array}$} & 23.629 & 18.174 & 5077 & 378 \\
\hline & $(0,2)$ & $(0,0)$ & $(0,9)$ & $(0,0)$ & & $(5,2)$ & $(5,5)$ & $(4,6)$ & $(3,5)$ \\
\hline \multirow{2}{*}{$\begin{array}{l}\text { Los empleos } \\
\text { que encontró } \\
\text { estaban mal } \\
\text { pagados }\end{array}$} & 1788 & 744 & 941 & 103 & \multirow{2}{*}{$\begin{array}{l}\text { Ahorros } \\
\text { personales }\end{array}$} & 231.507 & 166.577 & 59.883 & 5047 \\
\hline & $(0,4)$ & $(0,2)$ & $(0,8)$ & $(1,0)$ & & $(51,1)$ & $(50,4)$ & $(53,7)$ & $(47,0)$ \\
\hline \multirow{2}{*}{$\begin{array}{l}\text { Requería un } \\
\text { horario flexible }\end{array}$} & 6028 & 5251 & 777 & 0,0 & \multirow{2}{*}{ Otra fuente } & 33.055 & 22.470 & 9886 & 699 \\
\hline & $(1,3)$ & $(1,6)$ & $(0,7)$ & $(0,0)$ & & $(7,3)$ & $(6,8)$ & $(8,9)$ & $(6,5)$ \\
\hline \multirow{2}{*}{$\begin{array}{l}\text { No había } \\
\text { oportunidad de } \\
\text { empleo }\end{array}$} & 22.594 & 19.297 & 3297 & 0,0 & \multirow{2}{*}{$\begin{array}{l}\text { Heredó } \\
\text { el negocio }\end{array}$} & 24.140 & 23.984 & 46 & 110 \\
\hline & $(5,0)$ & $(5,8)$ & $(3,0)$ & $(0,0)$ & & $(5,3)$ & $(7,3)$ & $(0,04)$ & $(1,0)$ \\
\hline \multirow{2}{*}{ Otra razón } & 73.626 & 48.663 & 23.455 & 1508 & \multirow{2}{*}{$\begin{array}{l}\text { No lo } \\
\text { necesito }\end{array}$} & 52.148 & 29.129 & 22.360 & 659 \\
\hline & $(16,3)$ & $(14,7)$ & $(21,0)$ & $(14,1)$ & & $(11,5)$ & $(8,8)$ & $(20,0)$ & $(6,1)$ \\
\hline
\end{tabular}

a. La sumatoria de las frecuencias no dará el total de la muestra debido a los casos perdidos en la depuración de la base o simplemente porque no se contestó dicha pregunta al momento del levantamiento de la encuesta.

b. Las formas de asociación del micronegocio familiar, no familiar y mixto se representan con el número I, II y III, respectivamente.

c. Entre paréntesis se encuentra el porcentaje que representa el total.

Fuente: elaboración propia con datos de la Enamin (Inegi, 2012b).

La tabla 3 muestra cómo se relacionan las razones para continuar con el micronegocio con tres aspectos del desempeño: 1) las expectativas de continuar con el micronegocio dados los principales problemas que se enfrentan; 2) las bajas ventas, debido a que los clientes demandan (compran) productos importados de "menor precio"; y 3) exceso de competencia provocada por la informalidad de otros negocios del mismo giro. Se observa que, de manera global y familiar ( $34,8 \%$ y $45,8 \%$, respectivamente), las personas iniciaron un micronegocio con ayuda de su pareja u otro familiar. Por otro lado, en las asociaciones II y III se aprecia lo contrario, ya que fue el dueño u otra persona ajena a la familia quien inició el micronegocio. Así mismo, el 94,4\% de los microempresarios señaló que continuará con el micronegocio. 
Por otro lado, la totalidad de las personas que emprende un micronegocio reconoce que es necesario contar con una planta de personal calificado; por lo mismo, lleva a cabo los trámites necesarios para que el micronegocio permanezca como negocio "legal o formal" (32,9\%), aunque algunas veces por lo tardado e ineficiente del proceso decide no hacerlo. De la misma manera, los microempresarios hacen hincapié en que si el Gobierno les ofreciera o ellos encontraran un trabajo con las prestaciones de ley y con un ingreso superior al ingreso promedio ( $\$ 6834,70$ pesos) que obtienen en sus negocios, sin pensarlo, los dejarían (45,4\%).

\subsection{Estadísticos descriptivos}

Para poder determinar el efecto de las variables explicativas (véase tabla 4) sobre la probabilidad de que un microempresario mexicano se encuentre en una determinada forma de asociación, es necesario establecer que la variable ordenada es la forma de asociación, donde 1 indica si el microempresario se encuentra en la asociación familiar, 2 en la asociación no familiar y 3 en asociación mixta. Mientras, las variables independientes ${ }^{6}$ estarán conformadas por aquellos factores que fueron motivos o influyeron para emprender el micronegocio, como: edad del microempresario en años [Edad]; edad del microempresario al cuadrado [Edad2]; edad promedio de los microempresarios mayores de 22 años [edad_media]; género [Sexo: $1=$ Hombre, $0=$ no]; escolaridad [Esc1: 1 = Primaria, 0 = no; Esc2: 1 = Secundaria, $0=$ no; Esc3: $1=$ Preparatoria, $0=$ no; Esc4: $1=$ Carrera técnica, $0=$ no; Esc5: $1=$ Profesional, 0 = no; Esc6: 1 = Maestría, $0=$ no; Esc7: 1 = Doctorado, 0 = no; Esc_Total $=$ Grado de escolaridad promedio en años]; estado civil [Civil1: 1 = Unión

6 En el análisis de la muestra se incluyen variables de control, como edad, género, grados de escolaridad y estado civil, dado que los motivos o razones para emprender un micronegocio pueden no ser independientes a las variables explicativas. Peña et al. (2012) señalan que al analizar los resultados de este tipo de encuestas es importante tener en cuenta dos puntos. El primero es que los contrafactuales (es decir, situaciones hipotéticas alternativas a lo factual) no están bien definidos cuando se trata de los motivos por los que se inició el negocio. No solo no sabemos qué hubiera pasado si la misma persona hubiera iniciado el mismo negocio por un motivo diferente, ni siquiera sabemos si ese contrafactual tiene sentido: para algunas personas un motivo distinto podría ser incompatible con comenzar el negocio. Por ello, las estimaciones no deben interpretarse de manera causal sino solo como correlaciones que en principio pueden mostrar que los motivos importan. Los motivos no son variables que podamos alterar ceteris paribus sin esperar que haya inconsistencias. El segundo punto a considerar es que solo contamos con medidas ruidosas de los verdaderos motivos para iniciar el negocio. Los dueños pueden estar mintiendo o reportando con imprecisión los verdaderos motivos. Por esa razón, los coeficientes estimados para los motivos tienen un sesgo de atenuación (hacia cero). 


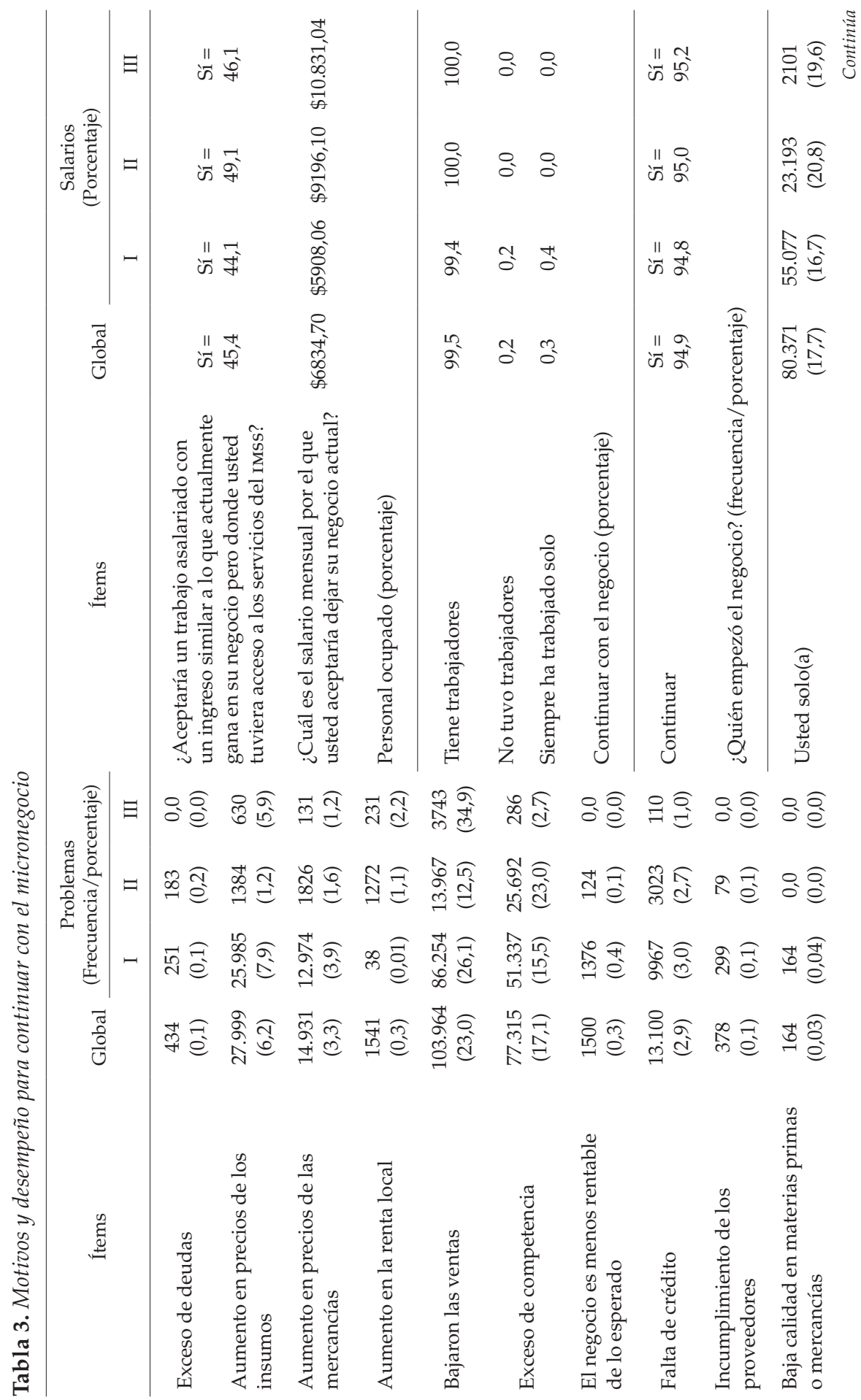




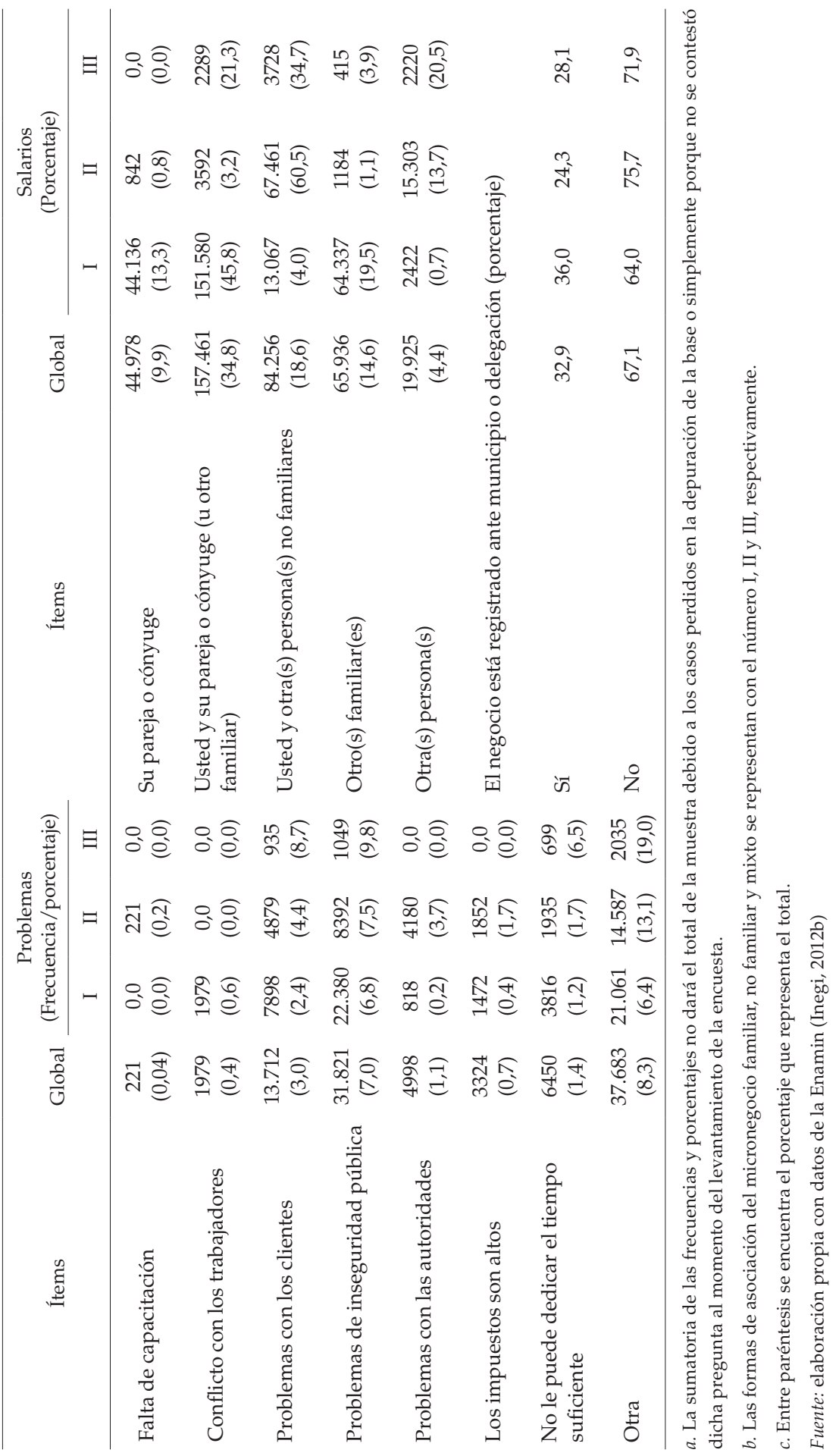


libre, 0 = no; Civil2: 1 = Divorciado, 0 = no; Civil3: 1 = Viudo, 0 = no; Civil4: 1 $=$ Casado, $0=$ no; Civil5: $1=$ Soltero, $0=$ no]; micronegocios por género $\left[p \_m u\right.$ jeres: porcentaje de micronegocios censales con jefatura femenina respecto al total de los micronegocios]; relación por género [razón: razón del total de hombres respecto al total de mujeres]; sectores económicos [sector1: número de micronegocios que pertenecen al sector manufactura; sector 2 : número de micronegocios que pertenecen al sector comercio; sector3: número de micronegocios que pertenecen al sector construcción; sector4: número de micronegocios que pertenecen al sector servicios]; herencia [Tradición: 1 = Si el micronegocio que tiene es por tradición familiar, o no =0]; complemento [Complementar: 1 = Si el micronegocio que tiene es para complementar el ingreso familiar, o no $=0$ ]; mejora del ingreso [Ingreso: 1 = Si el micronegocio es para mejorar el ingreso familiar, o no $=0$ ]; tenía dinero y encontró una oportunidad de negocios [Oportunidad: 1 = Se encontró una buena oportunidad de negocio por eso se decide emprender el micronegocio, o no $=0$ ]; profesión [Carrera: 1 = Si el micronegocio se emprende para ejercer su oficio o carrera, o no = 0]; única opción [Única: 1 = Si al emprender este micronegocio fue la única manera que tuvo para obtener un ingreso, o no $=0$ ]; experiencia [Experiencia: $1=\mathrm{Al}$ no tener experiencia requerida para un empleo decide emprender el micronegocio, o no =0]; alto nivel de escolaridad [Sobrecapacitado: 1 = Por estar sobrecapacitado para un empleo no le dieron el trabajo y decide emprender el micronegocio, o no =0]; empleos mal pagados [Mal_pagado: $1=\mathrm{Si}$ los empleos que encontró estaban mal pagados, o no = 0]; horarios flexibles [Horario: 1 = Por requerir un horario flexible emprende el micronegocio, $\mathrm{o}$ no = 0]; no había empleo [Desempleo: 1 = Al no haber oportunidad de empleo decide emprender el micronegocio, o no = 0]; y apoyo económico [Financiamiento: 1 = Si el microempresario aprovechó algún crédito o subsidio para emprender el micronegocio, o no $=0$ ].

En la tabla 4 se presentan las clásicas medidas de tendencia central; así mismo, se puede observar que la edad promedio de los microempresarios fue de 41 años. Según los datos de la Enamin (Inegi, 2012b), los microempresarios del sexo masculino fueron quienes más emprendieron un micronegocio en el periodo de estudio (61\%). Además, es posible observar que la mayor parte de los dueños de los micronegocios declaró tener estudios de educación superior (28\%) y secundaria (24\%). No obstante, el grado promedio de escolaridad alcanzada en la muestra fue de 11,23 años, lo que equivale a contar con estudios de educación media superior. En lo que respecta al estado civil, se aprecia que el $56 \%$ de los microempresarios se encuentra casado, y esta característica se puede interpretar como un motivo significante para emprender un micronegocio y mejorar el ingreso de la familia (22\%). 
168 Factores que influyen en el emprendimiento de un micronegocio familiar en México

Tabla 4. Estadísticas descriptivas de las variables

\begin{tabular}{|c|c|c|}
\hline Variable & Media & Desv. Std \\
\hline Edad & 40,67 & 13,121 \\
\hline Edad2 & 1825,71 & 1158,159 \\
\hline Edad_media & 44,04 & 9,537 \\
\hline Sexo & 0,61 & 0,489 \\
\hline Esc1 & 0,18 & 0,386 \\
\hline Esc2 & 0,24 & 0,430 \\
\hline Esc3 & 0,17 & 0,372 \\
\hline Esc4 & 0,07 & 0,257 \\
\hline Esc5 & 0,28 & 0,449 \\
\hline Esc6 & 0,02 & 0,143 \\
\hline Esc7 & 0,003 & 0,060 \\
\hline Esc_total & 11,23 & 4,133 \\
\hline Civil1 & 0,15 & 0,360 \\
\hline Civil2 & 0,02 & 0,143 \\
\hline Civil3 & 0,03 & 0,158 \\
\hline Civil4 & 0,56 & 0,496 \\
\hline Civil5 & 0,20 & 0,402 \\
\hline P_mujeres & 18,73 & 23,30 \\
\hline Razón & 1,09 & 0,00 \\
\hline Sector1 & 520,00 & 1305,78 \\
\hline Sector2 & 2900,61 & 4476,54 \\
\hline Sector3 & 81,30 & 364,27 \\
\hline Sector4 & 5021,74 & 4830,47 \\
\hline Tradición & 0,10 & 0,335 \\
\hline Complementar & 0,16 & 0,390 \\
\hline Ingreso & 0,22 & 0,424 \\
\hline Oportunidad & 0,06 & 0,244 \\
\hline Carrera & 0,15 & 0,292 \\
\hline Única & 0,09 & 0,296 \\
\hline
\end{tabular}




\begin{tabular}{lcc}
$\quad$ Variable & Media & Desv. Std. \\
\hline Experiencia & 0,0009 & 0,031 \\
Sobrecapacitado & 0,0009 & 0,030 \\
Mal_pagado & 0,01 & 0,074 \\
Horario & 0,01 & 0,117 \\
Desempleo & 0,05 & 0,223 \\
Financiamiento & 0,25 & 0,445
\end{tabular}

\section{Análisis empírico}

En este apartado se presenta el modelo empírico con el objeto de cuantificar los efectos de las variables explicativas sobre la probabilidad de que un microempresario mexicano se encuentre en un micronegocio con asociación familiar. Para ello, el modelo empleado es un logit ordenado, ya que la variable dependiente es discreta $\left(Y_{i}\right)$. En nuestro caso, el modelo expresa las preferencias de los microempresarios sobre una determinada forma de asociación del negocio, es decir, los motivos o razones del proceso de decisión, los cuales indican, implícitamente, un orden de utilidad y tienen, por tanto, un carácter ordinal.

En otras palabras, la valoración u opinión del microempresario puede definirse como una variable latente, $Y_{i}^{*}$, que es función de un conjunto de variables explicativas. De este modo, el rango de esta variable puede subdividirse en intervalos ordenados tales que, si la valoración del microempresario se sitúa en el intervalo $j$, el individuo elige la opción $j$, es decir, $Y_{i}=j, j=0, \ldots, J$.

La variable no observable o latente, $Y_{i}^{*}$, depende de un conjunto de variables explicativas que determinan la elección por parte del microempresario $i$, es decir:

$$
Y_{i}^{*}=\beta^{\prime} x_{i}+\varepsilon_{i}
$$

donde $Y^{*}$ es una variable no observable; $Y$ es la forma de asociación del micronegocio; $X$ es una matriz de variables explicativas que pueden ser tanto continuas como discretas; $\beta$ es el vector de coeficientes y $\varepsilon_{i}$ es un término de perturbación aleatoria. Por lo tanto, la elección del microempresario entre las alternativas $0, \ldots, J$ es reflejo del valor de $Y_{i}^{*}$ en relación con los umbrales $\mu_{j}, j=1, \ldots, J$, es decir: 


$$
Y_{i}=\left\{\begin{array}{c}
0, \text { si } Y_{i}^{*} \leq 0 \\
1, \text { si } 0<Y_{i}^{*} \leq \mu_{1} \\
2, \text { si } \mu_{1}<Y_{i}^{*} \leq \mu_{2} \\
\vdots \\
J, \text { si } \mu_{J-1}<Y_{i}^{*}
\end{array}\right\}
$$

Estos umbrales, desconocidos a priori, deben ser tales que $0<\mu_{1}<\mu_{2}<\ldots<\mu_{\mathrm{J}-1}$. Es decir, cualquiera que sea la decisión con alternativas ordenadas, dicha ordenación puede no implicar un orden implícito de utilidades. Así, lo apropiado será considerar que el microempresario elegirá la alternativa que le proporciona máxima utilidad. Con esta perspectiva, ligar la decisión al valor de la variable latente implica asumir que existe una función lineal de las variables explicativas de la decisión, tal que si dicha función toma valores entre $\mu_{\mathrm{J}-1} \mathrm{y}$ $\mu_{\mathrm{J}}$, la alternativa $j$ es la que proporciona máxima utilidad.

En este contexto, se asume que $\mu_{0}=0$. Por lo tanto, el modelo probabilístico que determina la elección queda definido de la siguiente manera:

$$
\begin{gathered}
P\left(Y_{i}=0\right)=P\left(Y_{i}^{*} \leq 0\right)=P\left(\varepsilon_{\mathrm{i}} \leq-\beta^{\prime} \mathrm{x}_{\mathrm{i}}\right), \\
P\left(Y_{i}=j\right)=P\left(\mu_{j-1}<Y_{i}^{*} \leq \mu_{j}\right)=P\left(\mu_{j-1}-\beta^{\prime} \mathrm{x}_{\mathrm{i}}<\varepsilon_{\mathrm{i}} \leq \mu_{j}-\beta^{\prime} \mathrm{x}_{\mathrm{i}}\right), j=1, \ldots, J-1, \\
P\left(Y_{i}=J\right)=P\left(Y_{i}^{*}>\mu_{J-1}\right)=P\left(\varepsilon_{\mathrm{i}}>\mu_{J-1}-\beta^{\prime} \mathrm{x}_{\mathrm{i}}\right)
\end{gathered}
$$

De tal forma que si la función de distribución de la variable aleatoria $\varepsilon i$ es F, entonces:

$$
\begin{gathered}
P\left(Y_{i}=0\right)=F\left(-\beta^{\prime} x_{\mathrm{i}}\right), \\
P\left(Y_{i}=j\right)=F\left(\mu_{j}<-\beta^{\prime} x_{\mathrm{i}}\right)-F\left(\mu_{j-1}-\beta^{\prime} x_{\mathrm{i}}\right), j=1, \ldots, J-1, \\
P\left(Y_{i}=J\right)=1-F\left(\mu_{j-1}-\beta^{\prime} x_{\mathrm{i}}\right)
\end{gathered}
$$

Así, para el modelo logit ordenado obtendríamos:

$$
F\left(\mu_{j-1}-\beta^{\prime} x_{i}\right)=\Delta\left(\mu_{j}-\beta^{\prime} x_{i}\right)=\frac{e^{\left(\mu_{j}-\beta^{\prime} x_{i}\right)}}{1+e^{\left(\mu_{j}-\beta^{\prime} x_{i}\right)}}, j=0, \ldots, J-1
$$

donde la estimación del modelo se lleva a cabo por máxima verosimilitud recurriendo a algoritmos iterativos de optimización y los umbrales se esti- 
man simultáneamente con los parámetros del vector $\beta$, común para todas las alternativas.

En cuanto a la interpretación de los resultados, los efectos marginales se obtienen de la siguiente forma:

$$
\begin{aligned}
& \frac{\partial P\left(Y_{i}=0\right)}{\partial x_{i m}}=-f\left(\beta^{\prime} x_{i}\right) \beta_{m,} \\
& \frac{\partial P\left(Y_{i}=0\right)}{\partial x_{i m}}=\left[f\left(\mu_{j-1}-\beta^{\prime} x_{i}\right)\right] \beta_{m}, j=1, \cdots, J-1, \\
& \frac{\partial P\left(Y_{i}=J\right)}{\partial x_{i m}}=f\left(\mu_{J-1}-\beta^{\prime} x_{i}\right) \beta_{m}
\end{aligned}
$$

siendo $f$ la función de densidad de la distribución del término de error que se haya elegido. Por lo tanto, para la primera y última de las alternativas, el signo del coeficiente pvermite conocer la dirección del cambio en la probabilidad de elección ante una variación en la variable $x_{m}$. En las alternativas intermedias, el resultado es ambiguo, dado que la dirección del cambio depende de los valores del vector de variables explicativas y, por supuesto, de los umbrales. Si la variable explicativa $x_{m}$ es un atributo, puede evaluarse el cambio discreto que experimentan las probabilidades de elección ante cambios en el valor de dicha variable.

\subsection{Resultados}

En la tabla 5 se presentan los resultados correspondientes a la estimación de un modelo logit ordenado para la forma de asociación de un micronegocio en México. Las alternativas que elige el microempresario según la Enamin son: $Y_{i}=1$, si la forma de asociación del micronegocio es familiar; $Y_{i}=2$, si la forma de asociación del micronegocio es no familiar; $Y_{i}=3$, si la asociación del micronegocio es mixta. Mientras, cada uno de los atributos explicativos de las probabilidades de elección de asociación se ha incorporado en términos de un conjunto de variables dummies que toman valor de 1 si el atributo en cuestión toma una modalidad determinada y de 0 en otro caso (véase sección 2.2 para mejor detalle de las variables explicativas).

Es importante mencionar que al correr en el modelo la función de Wald chi2 $(549,43)$, esta indica que el valor de los coeficientes es conjuntamente significativo para explicar la probabilidad de que los empresarios pertenezcan a una modalidad de micronegocio establecida por la Enamin. Así mismo, el 
valor de estadística de Prob > Chi2 (0,0000) indica que se puede rechazar en $1 \%$ la hipótesis de todos los coeficientes que sean iguales a 0 . Por último, la interpretación del Pseudo R2 establece que el 13,8\% de la variación de la variable dependiente puede ser explicada por la variación de las variables explicativas del modelo.

Tabla 5. Estimaciones y efectos marginales del modelo logit ordenado

\begin{tabular}{|c|c|c|c|c|c|c|c|c|}
\hline \multirow{2}{*}{ Variables } & \multicolumn{2}{|c|}{ Estimaciones } & \multicolumn{6}{|c|}{ Efectos marginales } \\
\hline & Coeficientes & $\mathrm{p}$-value & $\mathrm{P}\left(Y_{i}=1\right)$ & $\mathrm{p}$-value & $\mathrm{P}\left(Y_{i}=2\right)$ & p-value & $\mathrm{P}\left(Y_{i}=3\right)$ & $\mathrm{p}$-value \\
\hline Edad & $\begin{array}{l}, 0052 \\
(, 0299)\end{array}$ & 0,862 & $\begin{array}{l}-, 0010 \\
(, 0062)\end{array}$ & 0,862 & $\begin{array}{l}, 0009 \\
(, 0056)\end{array}$ & 0,862 & $\begin{array}{l}.00009 \\
(.0005)\end{array}$ & 0,862 \\
\hline Edad2 & $\begin{array}{l}-, 00001 \\
(, 0003)\end{array}$ & 0,956 & $\begin{array}{l}-, 00002 \\
(, 00007)\end{array}$ & 0,716 & $\begin{array}{l}, 00004 \\
(, 00007)\end{array}$ & 0,489 & $\begin{array}{c}-3.37 \mathrm{e}-07 \\
(.00001)\end{array}$ & 0,956 \\
\hline Edad_media & $\begin{array}{l}, 0049 \\
(, 0091)\end{array}$ & 0,589 & $\begin{array}{l}-, 0009 \\
(, 0018)\end{array}$ & 0,589 & $\begin{array}{l}, 0013 \\
(, 0016)\end{array}$ & 0,415 & $\begin{array}{c}.0001 \\
(.0001)\end{array}$ & 0,416 \\
\hline Sexo & $\begin{array}{l}, 8196^{* * *} \\
(, 1529)\end{array}$ & 0,000 & $\begin{array}{c}-, 1630^{* * * *} \\
(, 0286)\end{array}$ & 0,000 & $\begin{array}{l}, 1489^{* * * *} \\
(, 0268)\end{array}$ & 0,000 & $\begin{array}{l}.0140^{* * *} \\
(.0032)\end{array}$ & 0,000 \\
\hline Esc1 & $\begin{array}{l}, 5717 \\
(, 4702)\end{array}$ & 0,224 & $\begin{array}{l}-, 1265 \\
(, 1093)\end{array}$ & 0,247 & $\begin{array}{l}, 1139 \\
(, 0969)\end{array}$ & 0,240 & $\begin{array}{c}.0125 \\
(.0126)\end{array}$ & 0,321 \\
\hline Esc2 & $\begin{array}{l}, 2861 \\
(, 4698)\end{array}$ & 0,543 & $\begin{array}{l}-, 0611 \\
(, 1030)\end{array}$ & 0,553 & $\begin{array}{l}, 0555 \\
(, 0930)\end{array}$ & 0,551 & $\begin{array}{c}.0056 \\
(.0100)\end{array}$ & 0,576 \\
\hline Esc3 & $\begin{array}{l}, 6054 \\
(, 4874)\end{array}$ & 0,214 & $\begin{array}{l}-, 1347 \\
(, 1143)\end{array}$ & 0,239 & $\begin{array}{l}1212 \\
(, 1009)\end{array}$ & 0,230 & $\begin{array}{l}.0135 \\
(.0137)\end{array}$ & 0,321 \\
\hline Esc4 & $\begin{array}{l}, 6694 \\
(, 5134)\end{array}$ & 0,192 & $\begin{array}{l}-, 1526 \\
(, 1247)\end{array}$ & 0,221 & $\begin{array}{l}\text {,1363 } \\
(, 1083)\end{array}$ & 0,208 & $\begin{array}{c}.0163 \\
(.0167)\end{array}$ & 0,330 \\
\hline Esc5 & $\begin{array}{l}1,342^{* * *} \\
(, 4658)\end{array}$ & 0,004 & $\begin{array}{l}-, 3003^{* *} \\
(, 1060)\end{array}$ & 0,005 & $\begin{array}{l}2657^{* *} \\
(, 0896)\end{array}$ & 0,003 & $\begin{array}{l}.0345^{*} \\
(.0179)\end{array}$ & 0,054 \\
\hline Esc6 & $\begin{array}{l}1,076^{*} \\
(, 5918)\end{array}$ & 0,069 & $\begin{array}{l}-, 2552^{*} \\
(, 1461)\end{array}$ & 0,081 & $\begin{array}{l}, 2218^{*} \\
(, 1180)\end{array}$ & 0,060 & $\begin{array}{l}, 0333 \\
(, 0289)\end{array}$ & 0,249 \\
\hline Esc7 & $\begin{array}{l}2,684^{* * *} \\
(, 8697)\end{array}$ & 0,002 & $\begin{array}{c}-, 5657^{* * *} \\
(, 1065)\end{array}$ & 0,000 & $\begin{array}{l}, 3687^{* * *} \\
(, 0511)\end{array}$ & 0,000 & $\begin{array}{l}, 1970 \\
(, 1476)\end{array}$ & 0,182 \\
\hline Esc_total & $\begin{array}{l}, 0823^{* * *} \\
(, 0190)\end{array}$ & 0,000 & $\begin{array}{l}, 0171^{* * *} \\
(, 0038)\end{array}$ & 0,000 & $\begin{array}{l}, 0155^{* * *} \\
(, 0035)\end{array}$ & 0,000 & $\begin{array}{l}, 0015^{* * *} \\
(, 0004)\end{array}$ & 0,000 \\
\hline Civil1 & $\begin{array}{l}, 1665 \\
(, 2110)\end{array}$ & 0,430 & $\begin{array}{l}-, 0338 \\
(, 0439)\end{array}$ & 0,440 & $\begin{array}{l}, 0301 \\
(, 0415)\end{array}$ & 0,468 & $\begin{array}{l}, 0031 \\
(, 0044)\end{array}$ & 0,486 \\
\hline Civil2 & $\begin{array}{l}, 6691 \\
(, 5520)\end{array}$ & 0,225 & $\begin{array}{l}-, 1492 \\
(, 1337)\end{array}$ & 0,264 & $\begin{array}{l}, 1554 \\
(, 1146)\end{array}$ & 0,175 & $\begin{array}{l}, 0205 \\
(, 0205)\end{array}$ & 0,317 \\
\hline Civil3 & $\begin{array}{l}-, 5413 \\
(, 6012)\end{array}$ & 0,368 & $\begin{array}{l}, 0942 \\
(, 0900)\end{array}$ & 0,295 & $\begin{array}{l}-, 0913 \\
(, 0946)\end{array}$ & 0,334 & $\begin{array}{l}-, 0080 \\
(, 0074)\end{array}$ & 0,282 \\
\hline
\end{tabular}




\begin{tabular}{|c|c|c|c|c|c|c|c|c|}
\hline \multirow{2}{*}{ Variables } & \multicolumn{2}{|c|}{ Estimaciones } & \multicolumn{6}{|c|}{ Efectos marginales } \\
\hline & Coeficientes & $\mathrm{p}$-value & $\mathrm{P}\left(Y_{i}=1\right)$ & $\mathrm{p}$-value & $\mathrm{P}\left(Y_{i}=2\right)$ & $\mathrm{p}$-value & $\mathrm{P}\left(Y_{i}=3\right)$ & $\mathrm{p}$-value \\
\hline Civil4 & $\begin{array}{l}-, 5001^{*} \\
(, 2567)\end{array}$ & 0,051 & $\begin{array}{l}, 1080^{*} \\
(, 0571)\end{array}$ & 0,059 & $\begin{array}{l}-, 0978^{*} \\
(, 0514)\end{array}$ & 0,057 & $\begin{array}{l}-, 0102^{*} \\
(, 0060)\end{array}$ & 0,092 \\
\hline Civil5 & $\begin{array}{l}, 1427 \\
(, 2927)\end{array}$ & 0,626 & $\begin{array}{l}-, 0301 \\
(, 0628)\end{array}$ & 0,631 & $\begin{array}{l}, 0274 \\
(, 0570)\end{array}$ & 0,631 & $\begin{array}{l}, 0027 \\
(, 0058)\end{array}$ & 0,641 \\
\hline Sector1 & $\begin{array}{l}-, 0002^{* * * *} \\
(, 00006)\end{array}$ & 0,000 & $\begin{array}{l}, 00005^{* * *} \\
(, 00001)\end{array}$ & 0,000 & $\begin{array}{c}-, 00004^{* * * *} \\
(, 00001)\end{array}$ & 0,000 & $\begin{array}{c}-4,64 \mathrm{e}-06^{* * *} \\
(, 0000001)\end{array}$ & 0,000 \\
\hline Sector2 & $\begin{array}{l}-, 0001^{* * *} \\
(, 00002)\end{array}$ & 0,000 & $\begin{array}{l}, 00002^{* *} \\
(, 00001)\end{array}$ & 0,000 & $\begin{array}{c}-, 00002^{* *} \\
(, 00001)\end{array}$ & 0,000 & $\begin{array}{c}-2,26 \mathrm{e}-06^{* * *} \\
(, 0000001)\end{array}$ & 0,000 \\
\hline Sector3 & $\begin{array}{l}-, 0002 \\
(, 0001)\end{array}$ & 0,255 & $\begin{array}{l}, 00004 \\
(, 00004)\end{array}$ & 0,255 & $\begin{array}{l}-, 00003 \\
(, 00003)\end{array}$ & 0,256 & $\begin{array}{c}-3,74 \mathrm{e}-06 \\
(, 0000001)\end{array}$ & 0,263 \\
\hline Sector4 & $\begin{array}{l}, 00003 \\
(, 00003)\end{array}$ & 0,268 & $\begin{array}{r}7,06 \mathrm{e}-06 \\
(, 00001)\end{array}$ & 0,268 & $\begin{array}{l}6,41 \mathrm{e}-06 \\
(, 00001)\end{array}$ & 0,268 & $\begin{array}{c}6,46 \mathrm{e}-07 \\
(, 0000001)\end{array}$ & 0,276 \\
\hline Tradición & $\begin{array}{c}-1,178^{* * *} \\
(, 3329)\end{array}$ & 0,000 & $\begin{array}{l}, 1933^{* * * *} \\
(, 0398)\end{array}$ & 0,000 & $\begin{array}{c}-, 1789^{* * * *} \\
(, 0375)\end{array}$ & 0,000 & $\begin{array}{c}-, 0143^{* * * *} \\
(, 0036)\end{array}$ & 0,000 \\
\hline $\begin{array}{l}\text { Comple- } \\
\text { mentar }\end{array}$ & $\begin{array}{l}-, 2803 \\
(, 2643)\end{array}$ & 0,289 & $\begin{array}{l}, 0558 \\
(, 0501)\end{array}$ & 0,265 & $\begin{array}{l}-, 0511 \\
(, 0462)\end{array}$ & 0,268 & $\begin{array}{l}-, 0046 \\
(, 0040)\end{array}$ & 0,245 \\
\hline Ingreso & $\begin{array}{l}-, 1747 \\
(, 2245)\end{array}$ & 0,436 & $\begin{array}{l}, 0355 \\
(, 0446)\end{array}$ & 0,426 & $\begin{array}{l}-, 0325 \\
(, 0409)\end{array}$ & 0,427 & $\begin{array}{l}-, 0030 \\
(, 0037)\end{array}$ & 0,418 \\
\hline $\begin{array}{l}\text { Oportuni- } \\
\text { dad }\end{array}$ & $\begin{array}{l}, 0128 \\
(, 3493)\end{array}$ & 0,971 & $\begin{array}{l}-, 0026 \\
(, 0729)\end{array}$ & 0,971 & $\begin{array}{l}, 0024 \\
(, 0664)\end{array}$ & 0,971 & $\begin{array}{l}, 0002 \\
(, 0064)\end{array}$ & 0,971 \\
\hline Única & $\begin{array}{l}-, 0455 \\
(, 2777)\end{array}$ & 0,870 & $\begin{array}{l}, 0093 \\
(, 0568)\end{array}$ & 0,869 & $\begin{array}{l}-, 0085 \\
(, 0519)\end{array}$ & 0,869 & $\begin{array}{l}-, 0008 \\
(, 0048)\end{array}$ & 0,867 \\
\hline Experiencia & $\begin{array}{c}-11,109^{* * * *} \\
(1,043)\end{array}$ & 0,000 & $\begin{array}{l}, 2965^{* * *} \\
(, 0157)\end{array}$ & 0,000 & $\begin{array}{c}-, 2778^{* * * *} \\
(, 0146)\end{array}$ & 0,000 & $\begin{array}{c}-, 0187^{* * * *} \\
(, 0038)\end{array}$ & 0,000 \\
\hline Carrera & $\begin{array}{l}, 1778 \\
(, 2300)\end{array}$ & 0,439 & $\begin{array}{l}-, 0378 \\
(, 0501)\end{array}$ & 0,450 & $\begin{array}{l}, 0344 \\
(, 0454)\end{array}$ & 0,449 & $\begin{array}{l}, 0034 \\
(, 0047)\end{array}$ & 0,470 \\
\hline Mal_pagado & $\begin{array}{l}, 4358 \\
(, 8468)\end{array}$ & 0,607 & $\begin{array}{l}-, 0976 \\
(, 2015)\end{array}$ & 0,628 & $\begin{array}{l}, 0878 \\
(, 1782)\end{array}$ & 0,622 & $\begin{array}{l}, 0098 \\
(, 0234)\end{array}$ & 0,675 \\
\hline $\begin{array}{l}\text { Sobrecapaci- } \\
\text { tado }\end{array}$ & $\begin{array}{l}1,224^{* * * *} \\
(, 3784)\end{array}$ & 0,001 & $\begin{array}{l}-, 2922^{* * *} \\
(, 0916)\end{array}$ & 0,001 & $\begin{array}{l}, 2503^{* * *} \\
(, 0717)\end{array}$ & 0,000 & $\begin{array}{l}, 0419^{*} \\
(, 0217)\end{array}$ & 0,054 \\
\hline Horario & $\begin{array}{c}-, 096363 \\
(, 5942)\end{array}$ & 0,871 & $\begin{array}{l}, 0196 \\
(, 1185)\end{array}$ & 0,868 & $\begin{array}{l}-, 0179 \\
(, 1086)\end{array}$ & 0,869 & $\begin{array}{l}-, 0016 \\
(, 0099)\end{array}$ & 0,865 \\
\hline Desempleo & $\begin{array}{l}-, 2322 \\
(, 3199)\end{array}$ & 0,468 & $\begin{array}{l}, 0461 \\
(, 0604)\end{array}$ & 0,446 & $\begin{array}{l}-, 0422 \\
(, 0556)\end{array}$ & 0,448 & $\begin{array}{l}-, 0038 \\
(, 0048)\end{array}$ & 0,430 \\
\hline $\begin{array}{l}\text { Financia- } \\
\text { miento }\end{array}$ & $\begin{array}{l}-, 2194 \\
(, 1719)\end{array}$ & 0,202 & $\begin{array}{l}, 0445 \\
(, 0340)\end{array}$ & 0,190 & $\begin{array}{l}-, 0407 \\
(, 0312)\end{array}$ & 0,193 & $\begin{array}{l}-, 0038 \\
(, 0028)\end{array}$ & 0,183 \\
\hline
\end{tabular}

*** Significativa al 1\%. ** Significativa al 5\%. * Significativa al 10\%. (Error estándar entre paréntesis). 
En relación con las características individuales usadas como control, se destaca que el género del individuo es importante y significativo, puesto que la propensión de que un empresario (de género masculino) emprenda o inicie un micronegocio es 2,27 veces más que la del género femenino. Los resultados también muestran que las personas casadas (Civil4) son menos propensas a iniciar un micronegocio, es decir, la estimación de -0,5001 indica que los individuos casados disminuyen en promedio 0,5 unidades, lo que sugiere una relación negativa entre este estado civil con el inicio de un micronegocio, lo cual implica que si un individuo es casado, su oportunidad de crear o emprender uno es en promedio 1,65 menor que la de una persona soltera.

En cuanto al nivel de educación, los valores que encontramos son mixtos, pues, por un lado, si el empresario tiene estudios de nivel licenciatura o ingeniería (Esc5), la probabilidad de emprender un micronegocio en el periodo de estudio aumenta 3,83 veces más que si tuviera una maestría $(2,93)$. No obstante, con aquellos individuos que cuentan con un grado de doctorado la probabilidad de iniciar un micronegocio es aún mucho mayor en relación con los dos anteriores, ya que para cada año adicional de estudio, las oportunidades de emprender un micronegocio incrementan 14,65 veces más, manteniendo todo lo demás constante.

En nuestro análisis por tipo de sector económico, se observa que las personas que quieren iniciar un micronegocio están menos interesadas en emprenderlo en los sectores de la manufactura y comercio (Sector1 y Sector2), lo cual significa que si un individuo tiene pensado crear o emprender un micronegocio en estos sectores, su oportunidad de conseguirlo en promedio es 1,01 menor que si lo llevara a cabo en cualquier otro sector.

Otro resultado interesante que cabe mencionar es el ligado a los principales motivos que tienen las personas para iniciar un micronegocio, pues se observa que aquellas que heredan el negocio son menos propensas a iniciar otro micronegocio, ya que, por tradición familiar, se encuentran laborando en este. Esto quiere decir que si un individuo pertenece a esta categoría, su oportunidad de crear o emprender un micronegocio es en promedio 3,25 menor que si no lo hubiera heredado. Así mismo, se encuentra que aquellas personas que no cuentan con experiencia no serán capaces de iniciar una asociación en los diferentes tipos de micronegocio, ya que su oportunidad para emprenderlo es 66,8 menos; sin embargo, al estar sobrecapacitada, la oportunidad de crearlo es 3,40 veces más alta.

La interpretación de los efectos marginales es distinta, ya que los cálculos para los diferentes tipos de asociaciones aplicadas en este estudio son diferentes en cada columna $\left[\mathrm{P}\left(Y_{i}=1\right) ; \mathrm{P}\left(Y_{i}=2\right) ; \mathrm{P}\left(Y_{i}=3\right)\right]$. Por ejemplo, en la primera columna se muestran los efectos de las variables explicativas sobre 
la probabilidad de permanecer en $\mathrm{P}\left(Y_{i}=1\right)$, por lo que los signos positivos reflejan un efecto de permanencia y los signos negativos, uno de cambio hacia los demás. Por lo tanto, en las otras columnas se presenta la probabilidad de pasar a otras modalidades de asociación, es decir, un signo negativo se interpreta como una disminución en la probabilidad de estar en esa asociación y un signo positivo como la probabilidad de pasar a otra forma de asociación en los micronegocios.

A continuación se explican las variables que fueron significativas para la asociación de un micronegocio familiar, ya que por cuestiones de espacio se omitirán las otras dos formas de asociación —no obstante, el lector podrá hacer sus propias inferencias posteriormente.

El signo negativo en la variable de género (Sexo) muestra que entre mayor sea este indicador en la forma de asociación familiar, menor es la probabilidad de que sea hombre. No obstante, si se aprecian las columnas $\mathrm{P}\left(Y_{i}=2\right)$ y $\mathrm{P}\left(Y_{i}=3\right)$, se observa que las probabilidades de que sea un hombre quien emprenda o inicie un micronegocio en estas formas de asociación son de 14,8\% y 1,4\%, respectivamente.

En este mismo sentido, las variables de escolaridad (Esc5, Esc6 y Esc7) tienen un comportamiento similar, pues el signo de los coeficientes es negativo, y en la medida en que no se tiene una educación superior (estimada en años de estudios o grados de escolaridad), el impacto de crear o emprender un micronegocio es menor. Es decir, al no contar con un grado de escolaridad de licenciatura, maestría o doctorado, la probabilidad de iniciar un micronegocio familiar disminuye en alrededor del 30\%, 25,5\% y 56,5\%, respectivamente.

Por otro lado, los signos positivos de los coeficientes de la variable tradición, experiencia y civil4 muestran que si la persona hereda el micronegocio, la probabilidad de mantenerse y seguir en esta forma de asociación aumenta en $19,3 \%$. De igual manera, si la persona no tiene experiencia requerida para un empleo, la probabilidad de iniciar un micronegocio familiar se incrementa en un $29,6 \%$. En lo que respecta al estado civil, se observa que al estar casado se incrementa la probabilidad de iniciar un micronegocio familiar en 10,8\%.

\section{Conclusiones}

En este artículo se realizó un análisis descriptivo e inferencial de la Encuesta Nacional de Micronegocios en México para el 2012. En el análisis descriptivo se encuentra que los principales motivos que tienen los microempresarios para iniciar o emprender un micronegocio familiar son mejorar y complementar el ingreso de la familia. El 8,8\% argumenta que no necesitó algún tipo 
de financiamiento, ya que sus ahorros personales le permitieron emprender su propio micronegocio familiar $(50,4 \%)$. La mayor parte de los microempresarios encuestados parece tener una percepción positiva acerca de continuar con el micronegocio familiar $(94,8 \%)$, ya que sostiene que el Gobierno mexicano está implementando políticas, programas y fondos de apoyo para el fortalecimiento de este tipo de asociaciones.

Por último, podemos señalar que los resultados que se derivan del análisis inferencial ofrecen información relevante sobre los factores determinantes para iniciar un micronegocio. La aplicación de un modelo logit ordenado ha permitido determinar el efecto de algunas variables que inciden sobre la probabilidad de que una persona se encuentre en una determinada asociación de micronegocio, según la Enamin (Inegi, 2012b). Entre los principales hallazgos de este análisis se encuentra que:

1. Los hombres casados parecen ser los que más emprenden un micronegocio, ya que uno de sus principales motivos es complementar el ingreso familiar y dejar un patrimonio a su familia.

2. En este sentido, existe una preocupación de contar con un nivel de educación superior con el objetivo de tener una actividad empresarial y un ingreso extra para la familia.

3. En cuanto a los sectores económicos de mayor desarrollo para los micronegocios familiares, se encuentran el sector de manufactura y el del comercio. Sin embargo, los principales problemas a los que estos micronegocios se enfrentan día a día son tanto las bajas ventas debido a que los clientes compran productos importados de "menor precio", como el exceso de competencia por la informalidad de otros negocios de la misma actividad.

4. Finalmente, se observa que las variables explicativas más relevantes o significativas para cuantificar el efecto que tienen las personas para emprender un micronegocio familiar son la tradición, la experiencia y el estar sobrecapacitadas.

\section{Implicaciones y limitaciones académicas}

Desde el punto de vista académico, el presente trabajo ha pretendido contribuir al estudio de los micronegocios haciendo énfasis en el tipo de microempresas familiares. La investigación se ha realizado en un país que está en desarrollo y en el que los micronegocios constituyen el principal motor de la economía, ya que son considerados una fuente importante de empleo. Los 
pocos trabajos empíricos sobre los micronegocios familiares en México tienden a emplear técnicas descriptivas basadas principalmente en las medidas de tendencia central. En nuestro caso, también se ha utilizado la aplicación de un modelo logit ordenado.

A pesar de que esta técnica puede carecer de poder predictivo, entendemos que es un procedimiento válido para seleccionar, desde la perspectiva de la probabilidad de los microempresarios, aquellas variables que guardan ciertas relaciones significativas con la actividad de emprender un micronegocio familiar. Así mismo, se ha intentado desarrollar un trabajo riguroso respecto a la aplicación de un modelo de elección discreta binaria. En este estudio somos conscientes de las limitaciones y las oportunidades de mejora; por ejemplo, en el nivel conceptual, los resultados han planteado algunas cuestiones interesantes sobre los principales factores determinantes para emprender un micronegocio familiar en México, de manera que realizar un comparativo de las mismas variables en los diferentes estados o regiones de la República Mexicana podría mejorar el conocimiento, la percepción y las disyuntivas que se tienen en la actividad empresarial de esta asociación de negocio en la nación. Así mismo, es posible obtener conclusiones más sólidas si se lleva a cabo un comparativo por género y se aplican otras técnicas estadísticas en el análisis de la muestra, considerando los diferentes años de levantamiento de la Enamin; algunos ejemplos son el análisis de supervivencia utilizando las técnicas de tasas de incidencia, prevalencia, riesgos proporcionales de Cox, entre otros.

\section{Referencias}

Alonso, M. \& Galve, C. (2008). El emprendedor y la empresa: una revisión teórica de los determinantes a su constitución. Acciones e Investigaciones Sociales, 26, 5-44.

Álvarez, A. \& Valencia, P. (2008). Un análisis de los factores sociodemográficos determinantes en la creación de empresas en el marco de la interculturalidad. Revista de Economía Mundial, 18, 341-353.

Audretsch, D. \& Fritsch, M. (1994). The geography of firm births in Germany. Regional Studies, 28(4), 359-365.

Audretsch, D. (1995). Innovation and industry evolution. Cambridge: MIT Press.

Audretsch, D. \& Fritsch, M. (2002). Growth regimes over time and space. Regional Studies, 36, 113-124.

Bonfil, C. (2003). Fuentes de financiamiento para la microempresa en México. Aportes: Revista Mexicana de Estudios sobre la Cuenca del Pacífico, 31(5), 61-85. 
Casas, E. \& Ibarra, L. (2013). Análisis del impacto de crecimiento en las Pymes que se desarrollaron bajo un esquema de incubación: caso de estudio. Revista Internacional Administración y Finanzas, 6(3), 85-94.

Danco, L. (1980). Inside the Family Business. Cleveland, Ohio: The University Press.

De la Garza, M., Medina, J., Cheín, N., Jiménez, K., Ayup, J. \& J. Díaz. (2011). Los valores familiares y la empresa familiar en el nordeste de México. Cuadernos de Administración, 24(42), 315-333.

Duran, J. (2004). Determinantes del salario de reserva en el mercado laboral de CALI. Documento de trabajo. Elaborado dentro de las actividades investigativas del Grupo de investigación de Economía Laboral y Sociología del Trabajo. Recuperado de: http://econpapers.repec.org/paper/ col000149/004112.htm

Dussel, E. (2004). Pequeña y mediana empresa en México: condiciones, relevancia en la economía y retos de política. Economía UNAM, 1(2), 64-84.

Entrialgo, M., Fernández, E. \& Vázquez, C. (1999). Las características del propietario/directivo de la Pyme como factor determinante de su comportamiento emprendedor. Boletín de Estudios Económicos, 54(168), 405-424.

Fernández, E. \& Junquera, B. (2001). Factores determinantes en la creación de pequeñas empresas. Papeles de Economía Española, 89(90), 322-342.

Fölster, S. (2000). Do entrepreneurs create jobs? Small Business Economics, 14(2), 37-148.

García, C., Martínez, A. \& Fernández, R. (2010). Características del emprendedor influyentes en el proceso de creación empresarial y en el éxito esperado. Revista Europea de Dirección y Economía de la Empresa, 19(2), 31-48.

García, J. Álvarez, P. \& Reyna, R. (2007). Características del emprendedor de éxito en la creación de Pymes españolas. Estudios de Economía Aplicada, 25(3), 1-26.

Gelderen, M., Bosma, N. \& Thurik, R. (2001). Setting up a business in the Netherland: who starts, who gives up, who is still trying. Frontiers of Entrprneurship Research. Recuperado de http://www.babson.edu/entrep/fer/Babson2001/I/IG/IG.htm

Gómez, A., García, D. \& Marín, S. (2009). Restricciones a la financiación de la Pyme en México: una aproximación empírica. Análisis Económico, 57(24), 217-238.

Gómez, L. (2007). The process and problems of business Start-Ups. Pensamiento \& Gestión, 22, 232-255.

Guzmán, A. \& Trujillo, M. A. (2008). Emprendimiento social: revisión de literatura. Estudios Gerenciales, 24(109), 105-125. 
Hopenhayn, H. (1992). Entry, exit and firm dynamics in long run equilibrium. Econométrica, 60, 1127-1150.

Instituto Nacional de Estadística y Geografía - Inegi- (2012a). Directorio estadístico nacional de entidades económicas. Recuperado de http:/ / www.inegi.org.mx

Instituto Nacional de Estadística y Geografía - Inegi- (2012b). Encuesta Nacional de Micronegocios (Enamin) 2012. Recuperado de http: / / www3. inegi.org.mx/sistemas /tabuladosbasicos /tabdirecto.aspx?s=est\&c=33527

Kantis, H. (2003). Componentes macroeconómicos, sectoriales y microeconómicos para la estrategia nacional de desarrollo. Lineamientos para fortalecer las fuentes de crecimiento económico. Programa Multisectorial de Preinversión II préstamo BID 925 OC-AR, Estudio 1.EG.33.3, estudios sobre empleo, componente E: Creación y fortalecimiento de nuevas empresas, Ministerio de Economía de la Nación, Secretaría de Política Económica, Unidad de Preveinversión -Unpre-, Buenos Aires, Argentina.

Keeble, D. \& Walker, S. (1994). New firms, small firms and dead firms spatial patterns and determinants in the United Kingdom. Regional Studies, 28(4), 411-427.

Klepper, S. (1996). Entry, exit, growth, and innovation over the product life cycle. American Economic Review, 86(3), 562-583.

Lambson, V. (1991). Industry evolution with sunk costs and uncertain market conditions. International Journal of Industrial Organization, 9, 171-196.

Lecuona, R. (2009). El financiamiento a las Pymes en México: la experiencia reciente, Economía UNAM, 6(17), 69-91.

Martínez, E. (2008). Logit model como modelo de elección discreta: origen y evolución. Anuario Jurídico y Económico Escurialense, XLI, 470-483.

Mintzberg, H., Ahlstrand, B. \& Lampel, J. (1999). Safari a la estrategia. Una visita guiada por el management estratégico. Barcelona: Ediciones Juan Granica S.A.

Nava, E. (2013). Factores que influyen la creación de empresas Pymes y empresas familiares. International Journal of Good Conscience, 8(1), 11-22.

Peña, P., Ríos, I. \& Salazar, S. (2012). Los micronegocios en México: razones para emprenderlos, expectativas, tamaño y financiamiento. Estudios Económicos, 1, 77-94.

Pérez, C. (2005). Métodos estadísticos avanzados con SPSS. Editorial Thomson. Pinillos, M. (2001). Factores coadyuvantes para la creación de empresas en la Comunidad de Madrid. Papeles de Economía Española, 89(90), 343-361.

Quintana, C. (2001). Dimensiones del éxito de las empresas emprendedoras. Investigaciones Europeas de Dirección y Economía de la Empresa, 7(2), 139-158. 
Reynolds, P., Bygrave, W., Autio, E., Cox, L. \& Hay, M. (2002). Global entrepreneurship monitor. Executive Report. Wellesley: Babson Collage.

Secretaría de Economía (2013). Programa de Desarrollo Innovador 2013-2018. Recuperado de http:/ / www.economia.gob.mx

Ward, J. (1994). El crecimiento de la empresa familiar: retos específicos y mejores prácticas. Family businees Review, 7(2), 186-194. 